\title{
(2) OPEN ACCESS \\ Comparing negative health indicators in male and female veterans with the Canadian general population
}

\author{
Amy L Hall $\odot,{ }^{1}$ J Sweet, ${ }^{1}$ M Tweel, ${ }^{1}$ M B MacLean ${ }^{1,2}$
}

\begin{abstract}
Veterans Affairs Canada, Government of Canada, Charlottetown, Prince Edward Island, Canada

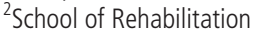
Therapy, Queen's University, Kingston, Ontario, Canada
\end{abstract}

\section{Correspondence to} Dr Amy L Hall, Veterans Affairs Canada, Government of Canada, Charlottetown, PEI C1A1L1, Canada; amy.hall@ canada.ca

Received 14 May 2020 Revised 17 July 2020 Accepted 18 July 2020

\section{Check for updates}

(c) Author(s) (or their employer(s)) 2020. Re-use permitted under CC BY-NC. No commercial re-use. See rights and permissions. Published by BMJ.

To cite: Hall AL, Sweet J, Tweel M, et al.

BMJ Mil Health Epub ahead of print: [please include Day Month Year]. doi:10.1136/ bmimilitary-2020-001526

\begin{abstract}
Introduction Sex-based information on differences between Canadian veterans and the general population is important to understand veterans' unique health needs and identify areas requiring further research. This study compared various health indicators in male and female veterans with their Canadian counterparts.

Methods Health indicators for recent-era Regular Force veterans (released between 1998 and 2015) were obtained from the 2016 Life After Service Survey and compared with the general population in the 2015-16 Canadian Community Health Survey using a crosssectional approach. Age-adjusted rates and $95 \% \mathrm{Cls}$ were calculated for males and females separately.
\end{abstract}

Results Compared with Canadians, veterans (both sexes) reported higher prevalence of fair or poor health and mental health, needing help with one or more activity of daily living, lifetime suicidal ideation and being diagnosed with mood and anxiety disorders, post-traumatic stress disorder, migraines, back problems, chronic pain, arthritis, ever having cancer, hearing problems, chronic pain and gastrointestinal problems. A higher prevalence of cardiovascular disease (all types) and high blood pressure was observed in male veterans compared with their Canadian counterparts. Within veterans only, males reported a higher prevalence of diagnosed hearing problems and cardiovascular disease compared with females; conversely females reported a higher prevalence of diagnosed migraines, mood, anxiety and gastrointestinal disorders, and needing help with activities of daily living. These sex differences are similar to the Canadian general population. Some similarities in reporting prevalence between male and female veterans (eg, fair or poor mental health, lifetime suicidal ideation, arthritis, asthma, lifetime cancer incidence, chronic pain and diabetes) were not observed in other Canadians.

Conclusion Male and female veterans differed from comparable Canadians, and from each other, in various areas of health. Further research is needed to explore these findings, and veteran-based policies and services should consider sex differences.

\section{INTRODUCTION}

In Canada, veterans (former officers or noncommissioned members of the Canadian Armed Forces, Regular or Reserve) represent approximately $3 \%$ of the adult population. ${ }^{1}$ A number of physical, lifestyle, psychological and exposure factors encountered during military service, ${ }^{2}$ and through the transition to civilian life, ${ }^{3}$ may contribute to long-term health and well-being

\section{Key messages}

Veterans represent approximately $3 \%$ of the Canadian adult population.

- Females represent an increasing proportion of military members globally with expanding roles in combat-related activities.

- While certain health outcomes in veterans have been researched and recognised, a limited literature base is available to describe other aspects of their physical and mental well-being, particularly stratified by sex.

- Both male and female veterans report a higher prevalence of many negative health conditions relative to their Canadian counterparts.

- Similarities in outcomes between male and female veterans underline a common experience of military service and its associated hazards; differences may reflect sex-based and gender-based factors noted elsewhere in the occupational health literature.

- Research and policies to support the health of veterans should consider sex differences.

effects that have not been comprehensively characterised in veterans. To date, the only national-level survey that has identified veterans and permitted health-based comparisons with the general population by sex is the 2003 Canadian Community Health Survey (CCHS), a large and nationally representative survey of the Canadian population. ${ }^{1}$ Veterans differed from their Canadian counterparts in many areas of health and well-being, including chronic conditions, mental health conditions and disability.

Assessments of veterans' health, and comparisons with the general Canadian population, should be regularly updated to inform research and planning for veterans' current and future needs. It is also important to investigate male and female veterans' health independently, since sex influences experiences during military service (including exposure to health hazards) and after release. ${ }^{45}$ Females account for approximately $14 \%$ of $630 \quad 000$ veterans currently residing in Canada, ${ }^{6}$ and $15.9 \%$ of Regular Force and Primary Reserve members of the Canadian Armed Forces. ${ }^{7}$ Female representation in the military is increasing in Canada and elsewhere $^{7-9}$ and the role of females in combat-related activities has expanded over time, ${ }^{8}$ supporting the need for research to understand their health 
and well-being. While some areas of veteran sex and gender research have broadened in recent years, ${ }^{4}$ Canadian information is scarce. ${ }^{10}$

The current study was conducted to examine and compare various negative health indicators of recent-era male and female veterans compared with their Canadian counterparts. This was done using a large and ongoing programme of research designed to better understand veteran health and wellness in Canada.

\section{METHODS}

The scope of the current cross-sectional analysis is the health domain of Veterans Affairs Canada's Well-being Surveillance Framework. ${ }^{11}$ Variables were selected from a standard set of population health indicators available for both veterans (in the 2016 Life After Service Studies (LASS) Survey) and the Canadian general population (in the 2015-16 CCHS). ${ }^{12}$

\section{Life After Service Studies (LASS) Survey}

The LASS programme of research was designed to investigate the transition from military to civilian life and ultimately improve the health of veterans in Canada. ${ }^{13}$ Four cycles of data collection, in 2010, 2013, 2016 and 2019, have been conducted to date.

The 2016 LASS collected data on veterans who released from the Regular Force between 1998 and 2015. Veterans were identified from a computer-generated listing of Canadian military releases. Entry ranks (includes Recruit, Officer Cadet, Second Lieutenant) were excluded from the LASS 2016 to incorporate design changes that included new content. Also excluded were out-of-scope records for those with a residence in the three Northern Territories (due to small numbers) or re-enrolled in the Canadian Armed Forces, as well as those residing outside of Canada, living in an institution, or deceased (for consistency with CCHS eligibility criteria).

Statistics Canada collected survey data using the Computer Assisted Telephone Interview in February and March 2016. The 2016 LASS target sample of 4121 individuals was representative (after weighting) of the 56419 Regular Force veterans released between 1998 and 2015 at postentry ranks (Officers, Senior Non-Commissioned Members and Junior Non-Commissioned Members). The survey had a $73 \%$ response rate $(n=2999)$, with $92 \%$ of respondents agreeing to share their data with Veterans Affairs Canada and the Department of National Defence $(\mathrm{n}=2755)$.

Additional details on the LASS survey and methodology, including indicator definitions used, are documented elsewhere. ${ }^{14-16}$

\section{Canadian Community Health Survey (CCHS)}

The CCHS is a national cross-sectional survey that collects information related to health status, healthcare utilisation and health determinants for the Canadian population. ${ }^{17}$ The survey, offered in both official languages, relies on a large sample of respondents and is designed to provide reliable health region level estimates every 2 years in Canada's 10 provinces and 3 territories. Exclusions from the CCHS sampling frame, including full-time members of the Canadian Forces and individuals based on their geographical or institutionalisation status, represent $<3 \%$ of the Canadian population aged 12 years and over.

Most comparator data for the general Canadian population were obtained from the CCHS 2015-16. CCHS 2015-16 data collection was carried out between January 2015 and December 2016, using computer-assisted in-person and telephone interviewing. Out of a total target sample of 185176 individuals in scope for the survey, a response rate of $59.5 \%$ (110 095) was obtained. Health indicators of interest that were not available in the CCHS 2015-16 version were obtained from prior CCHS versions.

Further details of the CCHS survey measures, methodology and quality control methods are reported elsewhere. ${ }^{17} 18$

\section{Analyses}

Comparisons between veterans and the Canadian general population were conducted using observed veteran distributions from the LASS and age-adjusted Canadian comparator data from the CCHS. Prevalence estimates incorporated survey sampling weights that accounted for both non-response and the complex stratified sampling designs of the LASS and the CCHS. Confidence Intervals (CIs were calculated at the 95\% level with the Stata SVY command using a Taylor series linearisation. Population estimates based on sample sizes less than 30 were suppressed for data quality, according to Statistics Canada guidelines. ${ }^{16}$ Analyses focused on all chronic disease variables assessed in the LASS 2016, with the exceptions of 'urinary incontinence' and 'Alzheimer's disease or other dementia', due to small response frequencies for both males and females. It also included variables addressing self-rated health, self-rated mental health, suicidal ideation and need for assistance with activities of daily living.

\section{RESULTS}

Population, sex and age characteristics for the sample of 2755 Regular Force veterans who released between 1998 and 2015, as well as their Canadian counterparts, are described in Table 1. Both male and female veterans in the LASS sample were younger than

Table 1 Study sample (unweighted), by sex and age

\begin{tabular}{|c|c|c|c|c|c|c|c|c|}
\hline & \multicolumn{4}{|c|}{$\begin{array}{l}\text { Veterans } \\
\text { (LASS 2016) }\end{array}$} & \multicolumn{4}{|c|}{$\begin{array}{l}\text { Canadian general population } \\
\text { (CCHS 2015-16) }\end{array}$} \\
\hline & \multicolumn{2}{|l|}{ Male } & \multicolumn{2}{|l|}{ Female } & \multicolumn{2}{|l|}{ Male } & \multicolumn{2}{|l|}{ Female } \\
\hline & Count & $\%$ & Count & $\%$ & Count & $\%$ & Count & $\%$ \\
\hline \multicolumn{9}{|c|}{ Age group (years) } \\
\hline$<30$ & 162 & 6.7 & 20 & 5.9 & 11290 & 22.2 & 11563 & 19.7 \\
\hline $30-39$ & 284 & 11.8 & 59 & 17.3 & 6701 & 13.2 & 8461 & 14.4 \\
\hline $40-49$ & 460 & 19.1 & 74 & 21.7 & 6771 & 13.3 & 7542 & 12.8 \\
\hline $50-59$ & 946 & 39.2 & 151 & 44.3 & 8531 & 16.8 & 9629 & 16.4 \\
\hline $60+$ & 562 & 23.3 & 37 & 10.9 & 17532 & 34.5 & 21639 & 36.8 \\
\hline Total & 2414 & 100 & 341 & 100 & 50825 & 100 & 58834 & 100 \\
\hline
\end{tabular}

CCHS, Canadian Community Health Survey; LASS, Life After Service Studies. 
Table 2 Observed prevalence of demographic characteristics, Canadian Regular Force Veterans (LASS 2016) and Canadian general population (CGP) (CCHS 2015-16), by sex*

\begin{tabular}{|c|c|c|c|c|c|c|}
\hline & \multicolumn{3}{|l|}{ Males } & \multicolumn{3}{|l|}{ Females } \\
\hline & Veterans & CGP & Veterans vs CGP & Veterans & CGP & Veterans vs CGP \\
\hline \multicolumn{7}{|l|}{ Marital status } \\
\hline \multirow[t]{2}{*}{ Married or common-law } & $77.5 \%$ & $72.4 \%$ & $V>C$ & $71.6 \%$ & $70.4 \%$ & $\mathrm{~V}=\mathrm{C}$ \\
\hline & (75.2 to 79.7 ) & (71.6 to 73.2 ) & & (64.7 to 77.6$)$ & (69.6 to 71.2 ) & \\
\hline \multirow[t]{2}{*}{ Separated, widowed or divorced } & $10.1 \%$ & $8.7 \%$ & $V=C$ & $13.0 \%$ & $14.2 \%$ & $\mathrm{~V}=\mathrm{C}$ \\
\hline & (8.6 to 11.9 ) & (8.3 to 9.1 ) & & (9.4 to 17.8 ) & (13.7 to 14.7$)$ & \\
\hline \multirow[t]{2}{*}{ Single, never married } & $12.3 \%$ & $18.9 \%$ & $\mathrm{~V}<\mathrm{C}$ & $15.4 \%$ & $15.4 \%$ & $\mathrm{~V}=\mathrm{C}$ \\
\hline & (10.6 to 14.3 ) & (18.1 to 19.7 ) & & (10.6 to 21.9$)$ & (14.7 to 16.1$)$ & \\
\hline \multicolumn{7}{|l|}{ Education } \\
\hline \multirow[t]{2}{*}{ Less than high school graduate } & $4.2 \%$ & $10.5 \%$ & $\mathrm{~V}<\mathrm{C}$ & $3.1 \%$ & $8.5 \%$ & $\mathrm{~V}<\mathrm{C}$ \\
\hline & (3.2 to 5.4 ) & (9.9 to 11.1 ) & & (1.3 to 7.3 ) & (7.9 to 9.1 ) & \\
\hline \multirow[t]{2}{*}{ High school graduate } & $42.8 \%$ & $21.8 \%$ & $V>C$ & $34.0 \%$ & $20.8 \%$ & $\mathrm{~V}>\mathrm{C}$ \\
\hline & ( 40.2 to 45.5 ) & (21.1 to 22.5 ) & & (27.2 to 41.5$)$ & (20.2 to 21.4 ) & \\
\hline \multirow[t]{2}{*}{ Postsecondary certification } & $53.0 \%$ & $67.7 \%$ & $\mathrm{~V}<\mathrm{C}$ & $62.9 \%$ & $70.7 \%$ & $\mathrm{~V}=\mathrm{C}$ \\
\hline & (50.3 to 55.7 ) & (66.9 to 68.5$)$ & & (55.4 to 69.9 ) & (70.0 to 71.4 ) & \\
\hline
\end{tabular}

${ }^{*}$ CCHS data age-adjusted to LASS distributions; all estimates incorporate survey sampling weights to account for both non-response and the complex stratified sampling designs of the LASS and the CCHS.

CCHS, Canadian Community Health Survey; LASS, Life After Service Studies.

the Canadian general population on average, with females representing $12.4 \%$ of veteran sample vs $54 \%$ of the general Canadian sample. Veterans were more likely than the general population to have a high school education and male veterans were more likely to be married or in a common law relationship compared with the Canadian general population (Table 2).

\section{Negative health indicators in veterans and Canadians}

Back problems and chronic pain were the most widely reported diagnosed chronic conditions in both male and female veterans (Table 3). Compared with their Canadian counterparts, male and female veterans reported a higher prevalence of fair or poor health and mental health, needing help with one or more activity of daily living, lifetime suicidal ideation and being diagnosed with mood and anxiety disorders, post-traumatic stress disorder, migraines, back problems, chronic pain, arthritis, ever having cancer, hearing problems, chronic pain and gastrointestinal problems. Cardiovascular disease (including heart disease, effects of stroke and/or high blood pressure (BP)) and high BP alone were more prevalent in male veterans compared with their Canadian counterparts. No differences were observed between male or female veterans and the general population for asthma, chronic obstructive pulmonary disease or diabetes.

\section{Within-veteran comparisons}

Within veterans only, males were more likely than females to report diagnosed hearing problems and cardiovascular disease. Female veterans were more likely than males to report diagnosed mood and anxiety disorders, migraines and gastrointestinal disorders, as well as needing help with one or more activity of daily living. These differences across sex are similar to those noted in the Canadian general population.

Some similarities between male and female veterans were not observed between sexes in the Canadian general population. Female non-veterans reported a higher prevalence than their male counterparts of: fair or poor mental health, lifetime suicidal ideation, arthritis, asthma, lifetime cancer incidence and chronic pain, all of which were reported equally in female versus male veterans. Male non-veterans reported a higher prevalence than females of diabetes; again, these outcomes were equally reported in male versus female veterans.

\section{DISCUSSION}

This study examined various health indicators in male and female veterans compared with their counterparts in the Canadian general population. Both groups of veterans fared less well than other Canadians for many, though not all, health outcomes assessed. Similarities noted between male and female veterans may reflect the common conditions experienced by both sexes during military service, while differences may be due to the influence of sex and gender on the military experience. ${ }^{45}$

The validity of our findings is generally supported by prior research over time and place, as described herein. A similar prevalence of fair or poor health has been reported by veterans in Australia (approximately 20\% overall) ${ }^{19}$ and in the UK (with 25\% of veterans reporting 'fair', 'bad' or 'very bad' health compared to $23 \%$ of non-veterans). ${ }^{20}$ In a recent nationally representative US-based study, male veterans were more (female veterans equally) likely to report fair or poor self-rated health compared to their civilian counterparts $\left(20.8 \%\right.$ vs $13.8 \%$ for males ${ }^{21}$ and $17.9 \%$ vs $17.5 \%$ for females ${ }^{22}$ ).

Functional limitations in both veterans and non-veterans have also been examined. In the UK in 2017 , health problems were reported to limit activity ' $a$ lot' for $26 \%$ and 'a little' for $35 \%$ of veterans versus for $24 \%$ and $31 \%$ of non-veterans. ${ }^{20}$ In Australian veterans aged $55+$ years, mild up to severe limitations have been observed in over 30\% of individuals not receiving Department of Veterans' Affairs payments and approximately two-thirds of those who do. ${ }^{19}$ A 2000 US Census-based study observed that both male and female veterans fared worse than non-veterans with respect to 'any limitation or disability', reported by $30 \%$ of female veterans (vs $24 \%$ of non-veterans) and $30 \%$ of male veterans (vs $22 \%$ of non-veterans)..$^{5}$ These veteran figures are similar to those reported in our study.

Recent national US estimates also indicate that veterans (65.3\% of males and $70.1 \%$ of females) are more likely to report pain compared with non-veterans $(51.8 \%$ of males and $60 \%$ of females). ${ }^{23}$ This greater prevalence in veterans is consistent with 
Table 3 Observed prevalence of self-reported negative health indicators*, Canadian Regular Force Veterans (LASS 2016) and Canadian general oopulation (CGP) (CCHS 2015-16)t, by sexł

\begin{tabular}{|c|c|c|c|c|c|c|}
\hline & Males & & & Females & & \\
\hline & Veterans & CGP & Veterans vs CGP & Veterans & CGP & Veterans vs CGP \\
\hline $\begin{array}{l}\text { Self-reported health } \\
\text { Fair or poor }\end{array}$ & $\begin{array}{l}22.4 \% \\
\text { (20.4 to } 24.6)\end{array}$ & $\begin{array}{l}10.6 \% \\
\text { (10.1 to } 11.1)\end{array}$ & $V>C$ & $\begin{array}{l}28.4 \% \\
\text { (22.4 to } 35.3 \text { ) }\end{array}$ & $\begin{array}{l}10.9 \% \\
\text { (10.4 to } 11.4)\end{array}$ & $V>C$ \\
\hline $\begin{array}{l}\text { Self-reported mental health } \\
\text { Fair or poor }\end{array}$ & $\begin{array}{l}20.1 \% \\
\text { (18.8 to } 23.3)\end{array}$ & $\begin{array}{l}5.8 \% \\
(10.3 \text { to } 11.3)\end{array}$ & $V>C$ & $\begin{array}{l}28.1 \% \\
\text { (20.8 to } 34.1 \text { ) }\end{array}$ & $\begin{array}{l}7.5 \% \\
(13.8 \text { to } 14.8)\end{array}$ & $V>C$ \\
\hline Suicidal ideation in lifetime & $\begin{array}{l}21.0 \% \\
\text { (18.8 to 23.3) }\end{array}$ & $\begin{array}{l}10.8 \% \\
(10.3 \text { to } 11.3)\end{array}$ & $V>C$ & $\begin{array}{l}26.9 \% \\
\text { (20.8 to 34.1) }\end{array}$ & $\begin{array}{l}14.3 \% \\
(13.8 \text { to } 14.8)\end{array}$ & $V>C$ \\
\hline Needs help with $1+A D L \dagger$ & $\begin{array}{l}18.7 \% \\
\text { (16.9 to 20.8) }\end{array}$ & $\begin{array}{l}6.2 \% \\
\text { (5.7 to } 6.7)\end{array}$ & $V>C$ & $\begin{array}{l}31.2 \% \\
\text { (25.2 to } 38.0)\end{array}$ & $\begin{array}{l}9.7 \% \\
(9.2 \text { to } 10.2)\end{array}$ & $V>C$ \\
\hline Mood disorder & $19.3 \%$ & $6.4 \%$ & $V>C$ & $29.0 \%$ & $11.8 \%$ & $V>C$ \\
\hline & (17.3 to 21.6$)$ & (6.0 to 6.8 ) & & (22.8 to 36.1 ) & (11.3 to 12.3$)$ & \\
\hline Anxiety disorder & $13.4 \%$ & $5.8 \%$ & $V>C$ & $22.7 \%$ & $10.7 \%$ & $V>C$ \\
\hline & (11.7 to 15.3 ) & (5.4 to 6.2 ) & & (17.1 to 29.5) & (10.2 to 11.2 ) & \\
\hline PTSD & $16.6 \%$ & $1.1 \%$ & $V>C$ & $14.9 \%$ & $2.8 \%$ & $V>C$ \\
\hline & (16.3 to 20.5) & (0.1 to 2.1 ) & & (13.1 to 24.1 ) & (1.8 to 3.8$)$ & \\
\hline Migraine & $11.2 \%$ & $6.4 \%$ & $V>C$ & $28.5 \%$ & $16.9 \%$ & $V>C$ \\
\hline & (9.6 to 13.1 ) & (6.0 to 6.8 ) & & (22.3 to 35.7 ) & (16.3 to 17.5 ) & \\
\hline Back problems & $40.9 \%$ & $21.2 \%$ & $V>C$ & $39.5 \%$ & $21.3 \%$ & $V>C$ \\
\hline & (38.4 to 43.6 ) & (20.6 to 21.8 ) & & (32.8 to 46.7 ) & (20.7 to 21.9 ) & \\
\hline Arthritis & $28.8 \%$ & $17.8 \%$ & $V>C$ & $31.5 \%$ & $21.1 \%$ & $V>C$ \\
\hline & (26.6 to 31.1 ) & (17.2 to 18.4 ) & & (25.4 to 38.3 ) & (20.5 to 21.7 ) & \\
\hline CVD: any type & $24.6 \%$ & $21.3 \%$ & $V>C$ & $12.1 \%$ & $15.5 \%$ & $V=C$ \\
\hline & (22.5 to 26.7 ) & (20.7 to 21.9 ) & & (7.9 to 18.0 ) & (14.9 to 16.1$)$ & \\
\hline CVD: heart disease & $4.7 \%$ & $4.4 \%$ & $V=C$ & $\mathrm{~F}$ & $2.3 \%$ & $\mathrm{~F}$ \\
\hline & (3.9 to 5.7 ) & (4.1 to 4.7 ) & & & (1.9 to 2.6$)$ & \\
\hline CVD: effects of stroke & $\mathrm{F}$ & $\begin{array}{l}1.0 \\
\text { (0.8 to } 1.2)\end{array}$ & $\mathrm{F}$ & $\mathrm{F}$ & $\begin{array}{l}0.6 \% \\
(0.4 \text { to } 0.8)\end{array}$ & $\mathrm{F}$ \\
\hline CVD: high BP & $\begin{array}{l}22.3 \% \\
\text { (20.3 to 24.4) }\end{array}$ & $\begin{array}{l}18.9 \% \\
\text { (18.3 to } 19.5)\end{array}$ & $V>C$ & $\mathrm{~F}$ & $\begin{array}{l}13.9 \% \\
\text { (13.3 to } 14.5)\end{array}$ & $\mathrm{F}$ \\
\hline Asthma & $5.7 \%$ & $6.4 \%$ & $V=C$ & $11.3 \%$ & $9.6 \%$ & $V=C$ \\
\hline & (4.6 to 7.1 ) & (6.0 to 6.8 ) & & (7.1 to 17.4 ) & (9.1 to 10.1 ) & \\
\hline COPD & $2.5 \%$ & $2.4 \%$ & $V=C$ & $2.9 \%$ & $2.8 \%$ & $V=C$ \\
\hline & (1.9 to 3.5 ) & (2.2 to 2.6 ) & & (1.4 to 6.1$)$ & (2.5 to 3.1 ) & \\
\hline Diabetes & $7.8 \%$ & $8.1 \%$ & $V=C$ & $3.2 \%$ & $5.4 \%$ & $V=C$ \\
\hline & (6.6 to 9.2 ) & (7.7 to 8.5 ) & & (1.5 to 6.7 ) & (5.0 to 5.8 ) & \\
\hline Cancer (lifetime incidence) & $6.9 \%$ & $3.7 \%$ & $V>C$ & $11.0 \%$ & $5.9 \%$ & $V>C$ \\
\hline & (5.9 to 8.1 ) & (3.4 to 4.0 ) & & (7.3 to 16.4 ) & (5.5 to 6.3 ) & \\
\hline Hearing problem & $13.0 \%$ & $2.9 \%$ & $V>C$ & $4.2 \%$ & $1.7 \%$ & $V>C$ \\
\hline & (11.5 to 14.8 ) & (2.6 to 3.2 ) & & (2.4 to 7.3 ) & (1.4 to 2.0$)$ & \\
\hline Chronic pain & $39.6 \%$ & $21.2 \%$ & $V>C$ & $49.4 \%$ & $25.5 \%$ & $V>C$ \\
\hline & (37.0 to 42.2 ) & (20.5 to 21.9 ) & & (42.2 to 56.6 ) & (24.9 to 26.1 ) & \\
\hline GI problem & $8.7 \%$ & $5.6 \%$ & $V>C$ & $15.8 \%$ & $9.4 \%$ & $V>C$ \\
\hline & (7.4 to 10.2 ) & (5.2 to 6.0 ) & & (11.4 to 21.4 ) & (9.0 to 9.8 ) & \\
\hline
\end{tabular}

${ }^{*}$ PTSD = Post traumatic stress disorder; CVD = cardiovascular disease (heart disease,effects of stroke or currently has high blood pressure); COPD = chronicbronchitis, emphysema or chronic obstructive pulmonary disease; $\mathrm{GI}$ =gastrointestinal (bowel disorders or ulcers); $\mathrm{ADL}$ = instrumentalactivity of daily living (iADL) or basic activity of daily living (bADL); $\mathrm{F}=$ Too few to calculate a reliable estimate

tPTSD obtained from the CCHS 2012 Mental Health Supplement ${ }^{47}$; COPD, hearing problem and GI problems obtained from CCHS 2013-14 ${ }^{17}$; chronic pain obtained from CCHS 2011-12. ${ }^{17}$ ‡CCHS data are age-adjusted to LASS distributions; all estimates incorporate survey sampling weights to account for both non-response and the complex stratified sampling designs of the LASS and the CCHS

bADL, basic activity of daily living; CCHS, Canadian Community Health Survey; COPD, chronic obstructive pulmonary disease; CVD, cardiovascular disease; F, too few to calculate a reliable estimate;

$\mathrm{Gl}$, gastrointestinal; iADL, instrumental activity of daily living; PTSD, post-traumatic stress disorder.

our results, and may reflect veterans' higher rates of back problems and arthritis compared with the Canadian general population. Musculoskeletal disorders, particularly low back issues, are a common cause of chronic pain and long-term physical disability, ${ }^{2425}$ and have been identified as a primary reason for military medical discharge, for example, as demonstrated in regular members of the UK Armed Forces. ${ }^{26}$ Also in agreement with our findings, US veterans have a greater likelihood of reporting back/neck problems and arthritis compared with non-veterans. ${ }^{27}$
Hearing impairments in veterans, including hearing loss and tinnitus, are well documented across countries. ${ }^{28-30}$ A significantly higher prevalence of severe hearing impairment has been observed in both male $(10.9 \%)$ and female $(4.0 \%)$ US veterans compared with non-veteran males $(2.3 \%)$ and females $(2.5 \%) .{ }^{21}{ }^{22}$ A similar prevalence of hearing difficulties has been observed in male UK veterans ( $11 \%$ vs $7 \%$ of non-veterans) but not in females (4\% vs $6 \%$ of non-veterans). ${ }^{20}$ These veteran prevalence estimates are similar to those reported in the current study, wherein both male 
and female veterans reported a higher prevalence of hearing problems relative to their Canadian counterparts. Furthermore, a threefold greater prevalence was noted in male compared with female veterans in our study, a difference that has also been observed in UK and US veterans. ${ }^{20} 30$

The lower prevalence of reported lifetime cancer incidence of veterans in the current study relative to other countries may relate to the relative youth of this population (including only individuals released from service since 1998). In line with our findings, US veterans have reported a higher prevalence of lifetime cancer diagnoses relative to their civilian counterparts $(17.8 \%$ vs $5.5 \%$ for males; $14.1 \%$ vs $10.7 \%$ for females). ${ }^{21} 22$ In Australia, Vietnam war veterans have reported a $13.4 \%$ lifetime prevalence of cancer diagnosis (elevated compared with age-matched males in that country's general population ${ }^{29}$ and higher rates of some cancers have also been noted in Korean war veterans. ${ }^{19}$ A study of Scottish veterans did not detect differences in overall cancer diagnoses in veterans compared with non-veterans, however increased risks of certain cancers (such as ovarian and breast cancers in females, and bladder and pancreatic cancers in males) were observed. ${ }^{31}$

A recent systematic review noted that reported rates of PTSD in general active duty and veteran populations varied from $11 \%$ to $14 \%$, with rates in injured service members ranging from $30.3 \%$ to $79 \%{ }^{32}$ Few systematic reviews have reported on prevalence rates of mental health issues other than PTSD (eg, depression, anxiety or other disorders) or physical health in veteran populations, nor on comparisons with rates in civilian populations. ${ }^{33}$ Our mental health results are consistent with prior (2010 and 2013) LASS survey cycles (also focused on veterans released from the Canadian Armed Forces since 1998), wherein poor self-rated mental health, mood disorders, anxiety disorders and PTSD was more prevalent compared with the general population. ${ }^{34}$ Rates of mental disorders in serving personnel have also been noted as similar to or greater than those of general populations in Canada ${ }^{35}$ and in Australia, with higher rates noted in recently discharged personnel versus actively serving members. ${ }^{19}$ A higher prevalence of poor mental health has been observed in deployed US male veterans and both deployed and non-deployed female veterans, compared with US civilians. ${ }^{36}$

Sex is a known factor in suicidal behaviour, with ideation being significantly more prevalent among females than males globally (although males are more likely to die by suicide). ${ }^{37} 38$ Our finding of greater prevalence of suicidal ideation in both male and female veterans is also in line with prior Canadian research that has observed increased rates of suicide among these two groups compared with the general Canadian population, with highest rates among males. ${ }^{39}$

\section{Strengths and limitations}

An important strength of this study is its sex-stratified approach to compare health outcomes in veterans with non-veteran Canadians. Although sex-based and gender-based analyses are widely recognised as an essential means to detect differences and provide insights for research and policy ${ }^{40}$ this approach is not consistently undertaken in studies of military and veteran populations. The small number of female respondents in the current study $(n=341)$ is reflected in the relatively wide confidence intervals for some conditions assessed. This underscores the need for targeted studies with larger numbers of females and greater power to examine health effects in potentially important subgroups to inform further research and policy decisions.

The comparability of results between veterans and other Canadians is strengthened by the LASS 2015-16 questions being based on those used in the CCHS. However, this study's reliance on selfreported data confers potential for reporting bias, which is difficult to estimate across the two surveyed populations. During service, Regular Forces personnel have regular access to a wide range of healthcare and rehabilitation services provided by the Canadian Armed Forces, ${ }^{41}$ which may have impacted some differences in selfreported diagnosed chronic conditions between veterans and other Canadians. Healthcare seeking behaviours also differ across males and females generally ${ }^{42}$ which could have impacted the prevalence of self-reported diagnosed conditions by sex (and provides additional support for sex-stratified analyses).

Veterans surveyed in this study are generally representative of the Canadian veteran population released from military service between 1998 and 2015, with full record linkage to Department of National Defence administrative data and a strong survey response rate of $73 \%$. Our findings cannot however be generalised to the full Canadian veteran population, since LASS 2016 included only Regular Force veterans who released between 1998 and 2015 and were above entry ranks at release. Furthermore, this sample was relatively young, with only $6 \%$ aged 65 years or older, and did not fully represent the eldest portion of the veteran population (age adjustment being unable to account for cohort and period effects). However, many of our results are comparable to earlier health comparisons between the full veteran population and other Canadians. ${ }^{1}$ Although veterans are not identified in the 2015-16 CCHS and could therefore not be excluded, they represent fewer than 3\% of those surveyed, and differences between veterans and the Canadian general population would be underestimated rather than overestimated.

While this paper focuses on describing negative indicators of health across veterans and Canadians, summaries of indicators for other well-being domains captured by the LASS 2016 are available elsewhere. ${ }^{14}{ }^{43}$ Inter-relations between various health indicators assessed in this study, as well as other well-being domains, merit further study. For example, employment status (eg, disability and unemployment) has been associated with veteran health, ${ }^{44}$ and commonly co-occurring chronic physical and mental health concerns have been observed to produce joint effects on work ability. ${ }^{45} 46$

This study's cross-sectional design does not permit an examination of health indicators over time, nor does it account for time since release from service. The longitudinal component of LASS may be leveraged in future analyses to examine how the transition from military to civilian life changes over time with respect to general health and well-being, chronic conditions, labour force participation and other factors.

\section{CONCLUSION}

The complexity of occupational and social factors encountered during and after military service identifies veterans as a subpopulation of Canadians who might require additional support. This is underscored by findings from the current study, which observed that both male and female veterans fared less well than the Canadian general population across a number of negative health indicators. These findings can be used to target future research to understand and improve the health of veterans in Canada and elsewhere. Research to examine the determinants of noted health disparities-including consideration of military service characteristics, sex and other social, employment and identity factors-is particularly warranted.

Contributors ALH and MBM conceptualised the work and interpreted the data. JS conducted data analysis. MT performed a literature review to inform interpretation. All authors contributed to drafting and critically revising the article. 
Funding The authors have not declared a specific grant for this research from any funding agency in the public, commercial or not-for-profit sectors.

Competing interests None declared.

Patient consent for publication Not required.

Ethics approval The data collection and data access procedures for both surveys were reviewed and approved by the relevant policy committees at Statistics Canada that fulfill the functions of a Research Ethics Board, following the principles of the Tri-Council Policy Statement: Ethical Conduct of Research Involving Humans.

Provenance and peer review Not commissioned; externally peer reviewed.

Data availability statement Data may be obtained from a third party and are not publicly available. Statistics Canada's microdata access guidelines are available at: https://www.statcan.gc.ca/eng/help/microdata.

Open access This is an open access article distributed in accordance with the Creative Commons Attribution Non Commercial (CC BY-NC 4.0) license, which permits others to distribute, remix, adapt, build upon this work non-commercially, and license their derivative works on different terms, provided the original work is properly cited, appropriate credit is given, any changes made indicated, and the use is non-commercial. See: http://creativecommons.org/licenses/by-nc/4.0/.

ORCID iD

Amy L Hall http://orcid.org/0000-0003-1502-2694

\section{REFERENCES}

1 MacLean MB, VanTil LD, Kriger D, et al. Well-Being of Canadian Armed Forces Veterans: Canadian Community Health Survey 2003 [Internet. Charlottetown, PE, Canada: Veterans Affairs Canada: Research Directorate Technical Report, 2013. http:/ publications.gc.ca/pub?id $=9.813559 \& \mathrm{~s} \mid=0$

2 Glass DC, Sim MR. The challenges of exposure assessment in health studies of Gulf War veterans. Philos Trans R Soc Lond B Bio/ Sci 2006;361:627-37.

3 Thompson J, MacLean M, Van Til L, et al. Survey on transition to civilian life: report on regular force veterans. Veterans Affairs Canada and Director General Military Personnel Research and Analysis, Department of National Defence 2011.

4 Bean-Mayberry B, Yano EM, Washington DL, et al. Systematic review of women veterans' health: update on successes and gaps. Womens Health Issues 2011;21:S84-97.

5 Wilmoth JM, London AS, Parker WM. Sex differences in the relationship between military service status and functional limitations and disabilities. Popul Res Policy Rev 2011;30:333-54.

6 Statistics Directorate. Veteran statistics. Veterans Affairs Canada, 2020.

7 Canada Department of National Defence. Statistics of women in the Canadian armed forces, 2020. Available: https://www.canada.ca/en/department-national-defence/ services/women-in-the-forces/statistics.html [Accessed 1 Jun 2020].

8 Kang HK, Bullman TA. Mortality among U.S. veterans of the Persian Gulf War. N Engl Med 1996;335:1498-504.

9 Park J. Perspectives on labour and income: a profile of the Canadian forces. Perspect Labour Income 2008.

10 Eichler M, Smith-Evans K. Gender in veteran reintegration and transition: a scoping review. J Mil Veteran Fam Health 2018;4:5-19.

11 Monitoring the Well-being of Veterans: A Veteran Well-being Surveillance Framework [Internet]. Charlottetown, PE, Canada: Veterans Affairs Canada. Available: http://publications.gc.ca/collections/collection_2017/acc-vac/V32-3472017-eng.pdf [Accessed 24 Jun 2020].

12 Statistics Canada. Health Indicators [Internet]. Government of Canada, 2019. Available: https://www150.statcan.gc.ca/n1/pub/82-221-x/82-221-x2017003-eng. htm [Accessed 3 Mar 2020].

13 Van Til L, MacLean MB, Thompson J, et al. Life After Service Studies: A Program of Population Health Research at Veterans Affairs Canada. In: Aiken AB, Bélanger SAH, eds. Shaping the future: military and veteran health research. Kingston, ON: Canadian Defence Academy Press, 2011: 317-22.

14 Van Til L, Sweet J, Poirier A, et al. Well-Being of Canadian Regular Force Veterans, Findings from LASS 2016 Survey [Internet. Charlottetown, PE, 2017. http:// publications.gc.ca/pub?id=9.839366\&sl=0

15 Statistics Canada. Life after service survey (LASS) detailed information for 2016, 2016. Available: www23.statcan.gc.ca/imdb/p2SV.pl?Function=getSurvey\&ld=257809 [Accessed 3 Mar 2020].

16 VanTil L, Poirier A, Sweet J, et al. Methodology : Life After Service Studies 2013. Charlottetown, PE, Canada: Veterans Affairs Canada, 2015. http://publications.gc.ca/ site/eng/9.629947/publication.html

17 Statistics Canada. Canadian Community Health Survey - Annual Component (CCHS), 2019. Available: https://www23.statcan.gc.ca/imdb/p2SV.pl?Function=getSurvey\& SDDS=3226 [Accessed 3 Mar 2020]

18 Statistics Canada. 2016 Canadian community health survey (CCHS) Microdata file user guide. Government of Canada, 2017.
19 Australian Institute of Health and Welfare. A Profile of Australia's Veterans 2018. Canberra, Australia: Australian Government, 2018. https://www.aihw.gov.au/reports/ veterans/a-profile-of-australias-veterans-2018/contents/summary

20 Government of the United Kingdom. Annual population survey: UK armed forces veterans residing in Great Britain 2017 [Internet]. GOV.UK, 2019. Available: https://www.gov.uk/government/statistics/annual-population-survey-uk-armedforces-veterans-residing-in-great-britain-2017 [Accessed 8 Mar 2020].

21 Hoerster KD, Lehavot K, Simpson T, et al. Health and health behavior differences. Am J Prev Med 2012;43:483-9.

22 Lehavot K, Hoerster KD, Nelson KM, et al. Health indicators for military, veteran, and civilian women. Am J Prev Med 2012;42:473-80.

23 Nahin RL. Severe pain in veterans: the effect of age and sex, and comparisons with the general population. J Pain 2017;18:247-54.

24 Fejer $\mathrm{R}$, Ruhe A. What is the prevalence of musculoskeletal problems in the elderly population in developed countries? A systematic critical literature review. Chiropr Man Therap 2012;20:31.

25 McBeth J, Jones K. Epidemiology of chronic musculoskeletal pain. Best Pract Res Clin Rheumatol 2007;21:403-25.

26 UK Ministry of Defence. Annual Medical Discharges in the UK Regular Armed Forces 1 April 2013 to 31 March 2018 [Internet], 2018. Available: https://assets.publishing service.gov.uk/government/uploads/system/uploads/attachment_data/file/829077/ 20180903-MedicalDisBulletinFinal-O-Legible.pdf

27 Hinojosa R, Hinojosa MS. Activity-Limiting musculoskeletal conditions in US veterans compared to non-veterans: results from the 2013 National health interview survey. PLoS One 2016;11:e0167143.

28 Senior SL. Health needs of ex-military personnel in the UK: a systematic review and qualitative synthesis. J R Army Med Corps 2019;165:410-5.

29 O'Toole BI, Catts SV, Outram S, et al. The physical and mental health of Australian Vietnam veterans 3 decades after the war and its relation to military service, combat, and post-traumatic stress disorder. Am J Epidemiol 2009;170:318-30.

30 Theodoroff SM, Lewis MS, Folmer RL, et al. Hearing impairment and tinnitus: prevalence, risk factors, and outcomes in US service members and veterans deployed to the Iraq and Afghanistan wars. Epidemiol Rev 2015;37:71-85.

31 Bergman BP. The Scottish veterans health study: a retrospective cohort study of 57,000 military veterans and 173,000 matched non-veterans [Internet] [PhD. University of Glasgow, 2015. https://eleanor.lib.gla.ac.uk/record=b3147374. (cited 2020 Mar 19).

32 Wall PLH. Posttraumatic stress disorder and traumatic brain injury in current military populations: a critical analysis. J Am Psychiatr Nurses Assoc 2012;18:278-98.

33 Oster C, Morello A, Venning A, et al. The health and wellbeing needs of veterans: a rapid review. BMC Psychiatry 2017;17:414.

34 Thompson JM, VanTil LD, Zamorski MA, et al. Mental health of Canadian armed forces veterans: review of population studies. J Mil Veteran Fam Health 2016;2:70-86.

35 Rusu C, Zamorski MA, Boulos D, et al. Prevalence comparison of Past-year mental disorders and suicidal behaviours in the Canadian armed forces and the Canadian general population. Can J Psychiatry 2016:61:46S-55

36 Hoglund MW, Schwartz RM. Mental health in deployed and nondeployed veteran men and women in comparison with their civilian counterparts. Mil Med 2014;179:19-25.

37 Borges G, Nock MK, Haro Abad JM, et al. Twelve-month prevalence of and risk factors for suicide attempts in the world Health organization world mental health surveys. J Clin Psychiatry 2010;71:1617-28.

38 Alicandro G, Malvezzi M, Gallus S, et al. Worldwide trends in suicide mortality from 1990 to 2015 with a focus on the global recession time frame. Int J Public Health 2019;64:785-95

39 VanTil LD, Simkus K, Rolland-Harris E, et al. Veteran suicide mortality in Canada from 1976 to 2012. J Mil Veteran Fam Health 2018;4:110-6.

40 Tannenbaum C, Ellis RP, Eyssel F, et al. Sex and gender analysis improves science and engineering. Nature 2019;575:137-46.

41 Zamorski MA, Boulos D. The impact of the military mission in Afghanistan on mental health in the Canadian armed forces: a summary of research findings. Eur J Psychotraumatol 2014;5:23822.

42 Thompson AE, Anisimowicz Y, Miedema B, et al. The influence of gender and other patient characteristics on health care-seeking behaviour: a QUALICOPC study. BMC Fam Pract 2016:17:38.

43 Pound T. Measuring Veteran Wellbeing [Internet. Charlottetown, PE, Canada: Veteran Affairs Canada, 2019. http://publications.gc.ca/collections/collection_2020/acc-vac/ V32-426-2020-eng.pdf

44 Tran TV, Canfield J, Chan K. The association between unemployment status and physical health among veterans and civilians in the United States. Soc Work Health Care 2016:55:720-31.

45 Kessler RC, Ormel J, Demler 0, et al. Comorbid mental disorders account for the role impairment of commonly occurring chronic physical disorders: results from the National comorbidity survey. J Occup Environ Med 2003;45:1257-66.

46 Murphy LB, Helmick CG, Allen KD, et al. Arthritis among veterans - United States, 2011-2013. MMWR Morb Mortal Wkly Rep 2014;63:999-1003.

47 Statistics Canada. Canadian Community Health Survey - Mental Health (CCHS) [Internet]. Government of Canada, 2011. Available: https://www23.statcan.gc.ca/ imdb/p2SV.pl?Function=getSurvey\&SDDS=5015 [Accessed 10 Mar 2020]. 